\title{
Linguistic Status of Markedness and Its Defining Criteria
}

\author{
Jianhong Yang \\ Tianjin University, Renai College, Tianjin, China
}

\section{Keywords: Markedness, Defining Criteria.}

\begin{abstract}
The article first addresses the theoretical prerequisites, and then conceptualizes markedness itself by exhibiting different linguistic concepts of markedness, finally, it elucidates the divergent criteria to define markedness, which produces a valid, feasible basis and theoretical rationale for the further study. To elaborate, it presents traditional view of markedness in terms of complexity principle and contextual neutralization as exemplified by phonemic variants, paradigmatic morphemes, semantic and pragmatic oppositions. Generative view of markedness has been demonstrated in typological, psycholinguistic and cognitive details. Besides, great efforts have been exerted to fully illustrate the defining criteria of markedness with top priority to generative and functionalistic interpretations.
\end{abstract}

\section{Introduction}

Markedness, a linguistic concept developed out of the Prague School, was elaborated by Trubetzkoy (1929, cited in Luelsdorff 2004) and Jokobson (1937, cited in Luelsdorff 2004) in their pioneering study of phonemic oppositions where phonetic symbols were literally marked to indicate additional features, such as voicing, nasalization or roundedness. In Prague School phonology, marked vs. unmarked, is a representational form developed to describe linguistic units on the basis of the presence or absence of the smallest semantically significant features. The element containing the feature is designated by $[+\mathrm{A}]$ which is the opposite of $[-\mathrm{A}]$ signifying the element without the feature ([A] standing for every possible linguistic feature). To elaborate, when two phonemes are distinguished, certain structures are often avoided while others are generated; the avoided structures are called 'marked' while the generated ones are 'unmarked'. Markedness is still an influential concept in current phonological theory. In Optimality Theory, many of the central arguments concerning constraints and ordering have to do with the markedness of a form. Furthermore, the concept of markedness has been extended to other areas of grammar as well (e.g., morphology, syntax and semantics, etc.), and is applied to every level and component of language in applied linguistics. Behind the theory are four leading ideas (de Lacy,

2006): Competence markedness, Preservation of the marked, Markedness conflation and Hierarchy conflict

\section{Traditional view of markedness}

\subsection{Complexity Principle}

The Complexity Principle, "Complexity in thought tends to be reflected in complexity of expression." (Clark and Clark 1978: 230) illustrates an accounting of markedness that is bound up with what they perceive as the relationship of language to thought. Complexity of expression can, in turn, be stated directly in markedness terms (Greenberg 1966). Moreover, research findings in psycholinguistics (Clark 1973) show that comprehension of more complex items requires slightly more processing time. For instance, in terms of the traditional category of mood, the verb forms employed in real conditions are generally considered to be indicative, while those employed in unreal and past unreal conditions are considered to be subjunctive and conditional. Greenberg (1966: 86) presents evidence from a variety of languages to support the unmarked status of the indicative mood vis-à-vis various "hypothetical modes"; "Primary is the difference between the indicative from which 
statements can be formed which are true or false and the various non-indicatives, imperatives, hortatives, subjunctives, optatives, etc."

In real conditions the time reference of the verb forms is as it would be on nonconditional sentences except for the fact that future time in the if-clause is expressed by the present tense form. In conditional sentences the relevant context is ...if.... In unreal conditions the use of the past tense in the if-clause is an indicator of unreality or improbability rather than that of the true past tense, and in past unreal conditions the use of the past perfect is an indicator both of unreality and past time. The use of modal forms in the main clause of unreal and past unreal conditions virtually always denotes conditionality, even in isolation. Thus, such sentences as She would give him a present. I would have called you. imply the contingency of an antecedent even though one is absent.

Consequently, the unmarked status of indicative forms used in real conditions relative to the marked status of the nonindicative forms used in unreal and past unreal conditions could be established in terms of the complexity principle: 'more complex' is reflected in the addition of morphemes, the addition of features, or the addition of rules. 'More complex' is thus equated with more marked, which is of course a necessary oversimplification.

\subsection{Contextual Neutralization}

The corollary to the notion of complexity through the addition of something is the principle of contextual neutralization. According to Clark and Clark (1978: 231), "if expression A can neutralize in meaning in contexts that the almost equivalent expression B cannot, then B is more complex than A." It is not difficult to identify paired items, from phonology to semantics, that bear such a markedness relationship, i.e., where one member of the pair, but not the other, will always appear in certain specified contexts. It is unmarked category that appears in environments where the opposition between two (or more) categories is suppressed, i.e. in an environment or position of neutralization. Rutherford (1982) reviews most of the researches to data which have utilized the explanatory power of markedness theory in an attempt to understand second language acquisition, thus sheds light on several other studies whose results have greater meaning when markedness considerations are taken into account. A few examples would illustrate the point.

Phonology: Any given segment becomes marked by the addition of features for voicing, aspiration, nasalization, etc., their unmarked counterparts characterized by the absence of that feature, as reflected in the negative affix: voiceless, unaspirated, nonnasal, etc. In position of consonantal neutralization --e.g., for bilabial stops following word-initial /s/ in English --- only the unmarked of the contrasting pair may appear, in this case (voiceless) /p/.

Morphology: Additional morphemes serve typically to distinguish plural from singular, past from present, feminine from masculine, etc., where in each case the former is the marked member. Following Comrie's (1984) observation that more marked forms tend to have more "morphological material", basic unreal conditions (v-ed. would + v) are less marked than past unreal conditions (had + v-ed, would have v-ed) because the former contain three free forms while the latter five. And when neutralization occurs --- e.g., singular vs. plural in the first half of an English noun compound (bookshelf) --- it is again the unmarked member that appears. In a discussion about some random persons, 'he' is often used to refer to one of them.

The present tense is unmarked for English verbs, whereas the past tense is indicated by the adding of the inflectional morpheme '-ed' to the end. Similarly, male things are unmarked, while female things are marked with special ending like '-ess' (actress, poetess). The word doctor can technically refer to either man or woman, but woman doctor is used to indicate a female doctor. Alternatively, there are the conventional arguments for the unmarked status of the present forms relative to nonpresent forms on the basis of "zero expression" of a tense marker (Greenberg 1966: 87). That is, unlike the marker '-ed' of the past tense, the present tense lacks an affix denoting its time reference. Moreover, marked forms often lack categories such as person and number which the unmarked forms have. Thus the present tense reflects person and number (3sg. -s/es) while the past and future formations do not.

Lexicon: Positions of neutralization with polar adjectives, for example, force the appearance of the unmarked member, where the marked/complex item has been shown psycholinguistically to be the one 
of "lesser extent" (Clark 1973): How old/*young is she? (How big/*small is the house? How long/*short was the movie? How far/*slow does he work? etc.) The adjectives old and young can be considered unmarked and marked respectively, because whereas old can be used to ask a person's age as in (1a), young cannot, except in some very special sense as in (1b):

(1) a. How old is she? (= What is her age?)

b. How young is she? (= Is she as young as she makes out?)

Syntax: A marked form is a non-basic or less natural form. An unmarked form is a basic, default form. An additional rule is typically required to derive negative from affirmative, interrogative from declarative, passive from active, etc., where in each case the former is the more complex/marked member and requires greater cognitive processing time. And in neutralization it would be, for example, the declarative not the interrogative that emerges, since one can ask a question using declarative form (He's here already?) but not utter a declarative using question form.

Semantics: Markedness refers to the way words are changed or added to give a special meaning. The unmarked choice is just the normal meaning. In markedness theory, the "general meaning of a marked category states the presence of a certain property A; the general meaning of the corresponding unmarked category states nothing about the presence A and is used chiefly but not exclusively to indicate the absence of A " (Jakobson 1957: 5, cited in Luelsdorff 2004). The form of a word that is conventionally chosen to be the lemma form is typically the form that is the least marked. Male nouns, the unmarked forms, usually serve as general terms: e.g. in dog breeding, the male is known as the $d o g$ while the female is known as the bitch; in man (humanity), the male is known as the man, while the female is known as the woman; brotherhood of man includes all people, both men and women, while sisterhood refers only to women. The further one moves from 'ego' through kinship systems, for example, the more complex/marked becomes the relationship, as reflected in English by increasing lexical compounding: father > grandfather > great grandfather, etc.; brother > brother-in-law etc.; cousin $>$ first cousin $>$ first cousin once removed etc. And again, in position of neutralization it is the unmarked member that occurs: forefathers, soul brothers, kissing cousins, etc.

Pragmatics: Markedness refers more generally to a choice that has meaning. In general, when choosing the marked choice (the non-normal choice), the addresser is making a statement. There is meaning. For instance, the usual greeting Hi, how are you? may or may not even be answered. But as for Hi, how's your Dad? this is special. You are likely to think of the question as actually asking how your Dad is. It carries the implication that your Dad is not well. If it's normal for women to wear a dress to the office, wearing pants is a statement. It's a marked choice. When a man wears a suit to work, it doesn't normally have much meaning: it's just normal. The clothing is not interpreted as intentionally making a statement. In contrast, if they show up in shorts one day, it makes a statement. It will be seen as a deliberate choice, as having intentional meaning. It is said that most of what women do is marked, just as femaleness is marked in the language itself (Spolsky 2000). They don't seem to have as many neutral choices that say nothing special about them. Women's clothing and footwear is extremely varied, brightly colored, and unique. Even forms of address are very telling. In survey forms, there are usually four choices: one for men, three for women: Mrs. vs. Ms. vs. Miss cf. Mr. In fact, it's considered an embarrassment for two women at a party to be wearing exactly the same dress. But it could have 100 men in identical gray suits and no one would even notice. Similarly, men don't wear makeup, but women do. Make-up is just like adding '-ed' or '-ette' to a verb to create a special meaning.

\section{Generative view of markedness}

The formal definition of markedness is used within the framework of generative grammar, an approach that identifies marked structures by considering the acquisition task and the kinds of evidence available to first language (L1) learners. Basing on the postulation that the ability to acquire a human language is genetically determined, the theory of Chomsky (1980, 1981a, 1981b, 1981c, 1982, cited in Mazurkewich 1984a) holds that a child approaches the language learning task endowed with a 
Universal Grammar (UG) that comprises a rich set of innate principles that govern the emergence of language. From the point of view of acquisition, UG may be considered as playing an intermediary role relating a particular language being acquired and the linguistic input that is received by a learner.

The degree of markedness depends on whether a feature is part of the 'core' or the 'periphery' (Ellis 1994). The more something departs from UG the more it is marked; the central core is unmarked - the neutral, excepted form of human language. Periphrastic formations are considered marked relative to nonperiphrastic forms since they appear where an otherwise inflected category might be expected (Cook 1988). The prediction made by such a theory is that as soon as the linguistic input triggers a learner's awareness of the existence of a core rule in the grammar, that rule not only would be learned easily, but it would be learned on the basis of minimal exposure to that language as it is predicated on a principle of UG. In the case of noncore or unmarked rules, they would have to be learned on the basis of positive evidence of their existence in that grammar. They could not be assumed prior since their existence depends on a particular language whose parameters may be set in one way or another. In effect, marked rules represent the idiosyncratic features of a language, but they are not random. Rather, instantiation of their existence in a grammar will take time and they will take longer to learn than a related unmarked rule.

\subsection{Typological Markedness}

A typological approach to linguistic analysis provides a basis for identifying both which features are rare in a particular language and which ones common, which, in turn, determines that which features are marked and which ones unmarked. According to the typological school, markedness refers to universal categories that hold cross-linguistically (Greenberg 1966) in which certain functions are more frequent $\sim$ less marked and others less frequent $\sim$ more marked. The broad claim is that those features that are universal or present in most languages are unmarked, while those that are specific to a particular language or found in only a few languages are marked. Typological markedness presents the tendency of languages to show a preference for particular structures. This bias toward marked elements is consistent within and across languages, and conveys a great deal about what languages can and cannot. Studies in typology have favored the claim that the hierarchy of markedness of a particular feature relates to the hierarchy in which that feature is acquired as a first language (L1) as well as a second language (L2) (White 1990).

\subsection{Psychological Markedness}

A question that is not directly addressed by technical definitions of markedness concerns the psychological status of formally marked constructions. A common assumption is that markedness also involves psychological factors and will lead to acquisition and processing difficulties (White 1987). In other words, if something is cross-linguistically rare, this should also have psychological correlates that will influence the behaviour of individual learners. Kellerman (1985) argues explicitly for psycholinguistic markedness. Markedness for Kellerman has psychological meaning, in that "a structure or meaning will be marked in the NL if there are related syntactic structures which express the same message in psychologically simpler ways, or meanings of the same word or lexical unit which the native speaker considers more central" (Kellerman 1979: 38, cited in White 1987). Unfortunately, psychological markedness is hard to define independently and, as pointed out by Rutherford (1982), it tends to be circular (something is difficult, therefore marked; something is marked, therefore difficult). The formal learnability and implicational views of markedness, on the other hand, have the advantage of providing definitions that make use of independent criteria.

\subsection{Cognitive Markedness}

One of the most common uses of markedness relates to observations about asymmetries in the output, triggers, and undergoers of certain processes (de Lacy, 2006). Unmarked elements can be the sole output of processes, fail to trigger alternations, and undergo processes alone. In contrast, marked elements are rarely the output, are often the only triggering elements, and are often exempt from undergoing processes. The study of cognitive psychology shows that various categories built on the process of human world knowledge are mostly prototype categories by which people always know the novel things. People's cognitive and deducing process is always indirectional and asymmetric, and the 
process is always going form prototypical things $\sim$ the unmarked to non-prototypical ones $\sim$ the marked by deduction and not a converse one. The prototypical members or the unmarked have the salience of cognition, and they are easy to arouse the attention, and easy to be stored and accessed, and they appeal to human expectation and anticipation when they are formed in the concept (Comrie 1984). According to Cook (1988), markedness means departure from the usual 'neutral' form in one way or another; the black sheep is marked, the white sheep unmarked because sheep are expected to be white; the albino crow is marked because crows are expected to be black.

\section{Defining criteria of markedness}

\subsection{Chomsky's Criteria}

Chomsky's Criterion is set in terms of the amount of evidence required in L1 acquisition. Core features are considered unmarked because they require minimal evidence for acquisition, whereas peripheral rules are considered marked because they require much more substantial evidence. Marked structures are defined as those departing from core grammar and requiring specific evidence during the course of L1 acquisition (Chomsky \& Lasnik 1977, Chomsky 1981, cited in Cook \& Newson 2000). The child's initial hypothesis constitutes the unmarked case and is predetermined by universal grammar (UG). Marked options, suggesting that core grammar must be overridden in some way, require positive evidence to that effect and will not be hypothesized without such evidence (White 1987).

\subsection{Typological Criteria}

Eckman (1985) presents the notion of typological markedness defined implicationally: "a phenomenon or structure $\mathrm{X}$ in some languages is relatively more marked than some other phenomenon or structure $\mathrm{Y}$ if cross-linguistically the presence of $\mathrm{X}$ in a language implies the presence of $\mathrm{Y}$, but the presence of Y does not imply the presence of X."

\subsection{Zoble's Criteria}

Zobl (1983) offers three senses of markedness, in which rules can be marked.

(a) Typological Specialization. For example, the extraction of combien in French, which violates the universal tendency of languages to avoid non-extractable how in how + adjective phrases as in English, is thus deemed marked.

(2) a. I didn't realize how comfortable I was.

b. *I didn't realize how I was comfortable.

(b) Typological Inconsistency. Zobl cites the examples of German and Dutch, which permit two different word orders: SVO in main clauses and SOV in subordinate clauses. Thus, German and Dutch word order can be considered marked in relation to English word order, which displays a high level of consistency.

(c) Typological Indeterminacy. Typological indeterminate features are seen as marked. It occurs when the structure predicted on the basis of a language's overall typology is not found. For example, English, as a SVO language, might be expected to manifest a noun + adjective ordering, but does not do so.

\subsection{Croft's Criteria}

Croft (1990) reviews Greenberg's early work on linguistic universals and identifies three main types of evidence:

(a) Structure: this concerns the presence or absence of a feature. For example, one argument for treating masculine members of pairs like man/woman and waiter/waitress as the unmarked (read 'simpler', base) forms is the fact that English adds forms to produce the morphologically more complex feminine form, which is therefore marked. Similarly, morphemes are added to distinguish past from present, plural from singular, and so on, suggesting that present and singular are unmarked, whereas past and plural marked.

(b) Behavior: this concerns whether one element is grammatically more 'versatile' than another --the more versatile it is, the more unmarked it is. 
(c) Frequency: the unmarked value is likely to occur with greater frequency than the marked value, both in actual use (i.e. in actual text) and also in the world's languages.

\subsection{Functionalistic Criteria}

Functionalist Givón has established a different criterion of markedness. Givón (1979) argues that three main criteria can be used to distinguish the marked from the unmarked category in a binary grammatical contrast:

(a) Structure Complexity: the marked structure tends to be more complex (or large) than the corresponding unmarked one.

(b) Frequency Distribution: the marked category (figure) tends to be less frequent, thus cognitively more salient, than the corresponding unmarked category (ground).

(c) Cognitive Complexity: the marked category tends to be cognitively more complex — in terms of mental effort, attention demands of processing time --- than the unmarked one. The unmarked member is the one which requires less time for cognitive processing.

\section{Conclusion}

Having been explored and extended over the past decades, markedness exemplifies a range of theoretical approaches which are loosely-connected with respect to the evaluation of linguistic structure. From being introduced in the phonological analysis of binary oppositions, it has exerted its great potential ranging from functioning as a global semiotic principle, a means of identifying natural symmetries and language universals to a terminology for learning difficulties and prediction for acquisitional preferences. However, the details of how markedness is determined and what it implies are still in controversy, which inspires the researchers concerned with great interest.

\section{References}

[1] Battistella, E. L. and L. Edwin. 2013. Logic Of Markedness. New York Oxford University Press.

[2] Bardovi-Harlig, K. 2010. "Markedness and Salience in Second-Language Acquisition," Language Learning, 37 (3): 385-407.

[3] Battistella, E. L. 2012. Markedness: The Evaluative Superstructure of Language. Markedness: the Evaluative Superstructure of Language. State University of New York Press.

[4] Clark, H. 1973. "Space, Time, Semantics, and the Child," in Cognitive Development and the Acquisition of Language, Moore, eds. New York: Academic Press, pp. 27-63.

[5] Clark, H. \& Clark, E. 1978. "Universals, Relativity, and Language Processing, in Method and Theory, J. Greenberg, eds. Stanford: Stanford University Press, pp. 230-43.

[6] Comrie, V. 1984. Language Universals and Linguistic Typology. Oxford: Basic Blackwell.

[7] Cook, V. and Newson, M. 2000. Chomsky's Universal Grammar. Beijing: Foreign Language Teaching and Research Press.

[8] Croft, W. 1990. Typology and Universals. Cambridge: Cambridge University Press.

[9] Demuth, K. 2013. Markedness and the Development of Prosodic Structure. Glsa University of Massachusetts.

[10] de Lacy. P. 2006. Markedness: Reduction and Preservation in Phonology. Cambridge University Press.

[11]Eckman, F., L. Bell, and D. Nelson, 1988. "On the Generalization of Relative Clause Instruction in the Acquisition of English as a Second Language," Applied Linguistics, 9: 1-20.

[12]Ellis, R. 1994. The Study of Second Language Acquisition. Shanghai: Shanghai Foreign Language Education Press.

[13]Flack, K. 2014. "Templatic Morphology and Indexed Markedness Constraints," Linguistic Inquiry, 38 (4): 749-758.

[14]Givón, T. 1979. On Understanding Grammar. New York: Academic Press.

[15]Greenberg, H. 1966. Universals of Language. Cambridge, Mass.: MIT Press. 
[16]Luelsdorff, P. (2004). Prague School (1945-1990). Beijing: Beijing University Press.

[17] Mazurkewich, I. (1984). "Dative Questions and Markedness," in Universals of Second Language Acquisition. F. Eckman, L. Bell, and D. Nelson, eds. Rowley Massachusetts: Newbury House Publishers, Inc, pp. 119 -131.

[18]Kellerman, E. 1985. "Dative Alternation and the Analysis of Data: a Reply to Mazurkewich," Language Learning, 35: 91-106.

[19]Powers, D. M. W. 2011. "Evaluation: From Precision, Recall and F-Factor to ROC, Informedness, Markedness \& Correlation, "Journal of Machine Learning Technologies 2: 2229-3981.

[20]Rutherford, W. 1982. "Markedness in Second Language Acquisition," Language Learning, 32: 85-108.

[21] Spolsky, B. 2000. Sociolinguistics. Shanghai: Shanghai Foreign Language Education Press.

[22] White, L. (1990). "Second Language Acquisition and Universal Grammar," Studies in Second Language Acquisition, 12: 121-33.

[23]Zobl, H. 1983. "Markedness and the Projection Problem," Language Learning, 33: 293-313. 